\title{
Association of oral health behavior and the use of dental services with oral health literacy among adults in Tehran, Iran
}

\author{
Mohammad Mehdi Naghibi Sistani ${ }^{1}$, Jorma I. Virtanen ${ }^{2,3}$, Reza Yazdani ${ }^{4}$, \\ Heikki Murtomaa ${ }^{5}$
}

Correspondence: Dr. Mohammad Mehdi Naghibi Sistani Email: m.naghibi@mubabol.ac.ir
'Department of Community Oral Health, Oral Health Research Center, Faculty of Dentistry, Babol University of Medical Sciences, Babol, Iran,

${ }^{2}$ Department of Community Dentistry, Research Unit of Oral Health Sciences, University of Oulu, Oulu, Finland, ${ }^{3}$ Medical Research Center, Oulu University Hospital, Oulu, Finland,

${ }^{4}$ Department of Community Oral Health, School of Dentistry, Tehran University of Medical Sciences, Tehran, Iran,

${ }^{5}$ Department of Oral Public Health, Institute of Dentistry, University of Helsinki, Helsinki, Finland

\section{ABSTRACT}

Objective: To assess the association of oral health behavior (OHB) and the use of dental services with oral health literacy (OHL) among Iranian adults. Methods: This was a cross-sectional population study of a random sample of 1031 adults aged 18-65 in Tehran, Iran. We collected data on tooth brushing frequency, the consumption of sugary snacks and beverages, and time since last dental visit. To measure OHL, we used a validated OHL adults' questionnaire (OHL-AQ). In addition to descriptive analysis, we used multiple logistic regression models to assess the association of OHB and the most recent dental visit with OHL while controlling for socioeconomic and demographic factors. Results: The participants' mean age was 36.3 (standard deviation 12.9 ), and $51 \%$ were women. Of the participants, $81.3 \%$ reported brushing their teeth daily ( $\geq 1 /$ day), $37.6 \%$ consumed sugary snacks or beverages between meals less than once daily $(<1 /$ day), and $36.8 \%$ used dental services within the past 6 months. In the adjusted models, high OHL scores significantly correlated with daily $(\geq 1 /$ day) tooth brushing (odds ratio [OR] $=1.97$, $95 \%$ confidence interval [CI]: 1.30-2.98), the consumption of sugary snacks or beverages $(<1$ /day between meals) $(\mathrm{OR}=1.56$, 95\% CI: 1.13-2.15) and the recent use of dental services ( $\leq 6$ months) (OR $=1.59,95 \%$ CI: $1.15-2.21)$, respectively. Conclusions: OHL relates significantly to improved OHB and the use of dental services. Oral health promotion programs should, therefore, take into account improvements in adults' OHL, particularly in countries with developing health-care services.

Key words: Oral health behavior, oral health literacy, use of dental services

\section{INTRODUCTION}

Oral health literacy (OHL) skills are intended to help individuals to act on oral health information, to use

\begin{tabular}{|l|l|}
\hline \multicolumn{2}{|c|}{ Access this article online } \\
\hline Quick Response Code: \\
\hline
\end{tabular}

This is an open access article distributed under the terms of the Creative Commons Attribution-NonCommercial-ShareAlike 3.0 License, which allows others to remix, tweak, and build upon the work non-commercially, as long as the author is credited and the new creations are licensed under the identical terms.

For reprints contact: reprints@medknow.com

How to cite this article: Naghibi Sistani MM, Virtanen JI, Yazdani R,
Murtomaa H. Association of oral health behavior and the use of dental
services with oral health literacy among adults in Tehran, Iran. Eur J
Dent 2017;11:162-7.
DOI: $10.4103 /$ ejd.ejd_332_16


the health-care system, and to communicate actively with oral health professionals. ${ }^{[1]}$ OHL has proved to be critical in reducing oral health disparities and in promoting oral health. ${ }^{[2]}$ Low OHL predicts poor self-reported oral health ${ }^{[3,4]}$ and poor periodontal status. ${ }^{[5]}$ While previous findings clarified the effect of health literacy on health-care utilization, ${ }^{[6,7]}$ the relationship between OHL and dental service utilization remains inconsistent.

Limited OHL has proved to be a barrier to Canadian immigrants' participation to the oral health-care system and their use of dental services. ${ }^{[8]}$ Canadian adults who visited the dentist regularly had significantly higher OHL scores than did those who visited the dentist only to address pain. ${ }^{[9]}$ Similarly, Jamieson et al..$^{[10]}$ reported that indigenous Australians with no recent dental visits ( $<1$ year ago) had lower OHL scores. Conversely, earlier studies found a nonsignificant association between OHL and dental care visits among American adults. ${ }^{[11,2]}$ Burgette et al..$^{[13]}$ also found that dental utilization as measured by time since last dental visit was a poor predictor of OHL scores.

Although long-standing poor oral health behavior $(\mathrm{OHB})$ such as infrequent dental visits and tooth brushing as well as frequent use of sugary snacks and drinks could result from limited OHL, ${ }^{[14]}$ findings about the association between OHL and $\mathrm{OHB}$ are contradictory. Ueno et al. ${ }^{[14]}$ found that adults with poor $\mathrm{OHB}$ and clinical status to have lower OHL scores. Low OHL scores also associated significantly with lower tooth brushing frequency among older adults. ${ }^{[15]}$ Respectively, caregiver's lower levels of OHL associated with their children's poor OHB. ${ }^{[16,17]}$ In contrast, the association of OHL with $\mathrm{OHB}^{[18]}$ and OHL with dental neglect ${ }^{[19]}$ was proved to be nonsignificant after adjusting for sociodemographic variables.

Despite conflicting reports on the association of $\mathrm{OHB}$ and dental visits with OHL, data on these relations in countries with developing oral health-care systems, such as Iran, are unavailable. The present study, therefore, aimed to assess the association of $\mathrm{OHB}$ and the use of dental services with OHL among Iranian adults.

\section{METHODS}

\section{Design and data collection}

In 2011, we conducted this cross-sectional population-based survey of 1031 adults in the Iranian capital, Tehran. Tehran's eight million inhabitants cover a broad range of socioeconomic backgrounds. Interviewers from the Iranian Students' Polling Agency, a professional agency, assisted with the data collection. To reduce inter-interviewer variability, all interviewers participated in a training session, in which the head researcher explained the questionnaire protocols.

\section{Sampling}

Multistage random area served as the sampling method, and the sample size was calculated by estimating a single proportion. All 22 districts of Tehran served as individual strata, each weighted according to its population. Within each stratum, we sampled clusters at random. We then randomly selected subsequent blocks of houses from each cluster until we had systematically selected ten houses from each block. Finally, we randomly selected individuals from the adults residing in the same house. We excluded any adults who were illiterate in Persian (the local language). ${ }^{[3]}$

\section{Questionnaire}

Oral Health Literacy-Adults Questionnaire (OHLAQ), which proved to be a valid and reliable instrument, served to measure adults' OHL levels. ${ }^{[20]}$ The questionnaire contains 17 items into four sections: reading comprehension (to assess reading literacy and oral health knowledge), numeracy (be able to calculate in a dental prescription and a mouth-rinse instruction), listening (to evaluate the effectiveness of the patient's communication skills), and decision-making (to show the ability to apply literacy skills related to common oral health problems and items extracted from the medical history form).

The correct answers were scored as 1 ; incorrect or missing answers, 0 . The total score for the questionnaire ranged from 0 to 17 . We classified the OHL-AQ scores into three levels: inadequate (0-9), marginal (10-11), and adequate (12-17) which was tested and validated in the pilot study. ${ }^{[20]}$

\section{Measures}

We measured $\mathrm{OHB}$ with self-reported questions about tooth brushing habits and consumption of sugary snacks or beverages between daily meals. Response alternatives for frequency of tooth brushing were "twice or more daily", "once daily", and "less than once daily," but for the regression analysis were dichotomized as "once or more daily $(\geq 1 /$ day)" and "less than once daily $(<1 /$ day)" based on optimal tooth brushing. ${ }^{[21]}$ We categorized the consumption 
of sugary snacks or beverages between daily meals "once or more daily ( $\geq 1 /$ day)" and "less than once daily (<1/day)" as an optimal OHB. ${ }^{[22]}$ Finally, we classified the use of dental services "within the last 6 months ( $\leq 6$ months)" and "more than 6 months ago ( $>6$ months)" according to the guidelines of the American Academy of Pediatric Dentistry ${ }^{[23]}$ and the Iranian Dental Association. ${ }^{[24]}$

Background data included age, gender, level of education, and economic status. We categorized age as: 18-24, 25-44, or 45-65 years but used noncategorical age in the regression models. We measured education in years and dichotomized it as either: "1-11" or "12 years and more." Formal education served as the social level, which previous health studies have shown to be an accurate indicator. ${ }^{[25,26]}$ Living area in square meters per person $\left(\mathrm{m}^{2} / \mathrm{p}\right.$, where $P$ included children) served as the measure of economic status, a valid and reliable indicator of economic status in Iran. ${ }^{[3,26]}$ We categorized this proxy measure on three levels: $<20,20-39$, and $\geq 40 \mathrm{~m}^{2} / \mathrm{p}$.

\section{Statistical analysis}

In addition to descriptive statistics, we used Chi-square test to assess the significant difference between $\mathrm{OHB}$ and the use of dental services with demographic and socioeconomic background factors. We used three multiple logistic regression models to estimate the factors related to the outcome variables "self-reported OHB" and "use of dental services" with odds ratios (ORs). The regression models were adjusted by the following independent variables: age, gender, educational level, living area in square meters per person $\left(\mathrm{m}^{2} / \mathrm{p}\right)$, and OHL. Significance was set at $<0.05$. We analyzed all data with SPSS software, version 22 for Windows (SPSS Inc., Chicago, IL, USA).

\section{Ethics}

The ethics committee of the Tehran University of Medical Sciences approved the study. Before being invited to take part, participants received information about the scientific goal of this research that their participation was voluntary and that they could withdraw at any time.

\section{RESULTS}

The participants' OHB and use of dental services according to demographic and socioeconomic background factors appear in Table 1. Overall, 81.3\% of the participants reported brushing their teeth once or more daily, while $9.7 \%$ reported rarely or never brushing their teeth. Of the participants, $62.4 \%$ reported consuming sugary drinks and beverages between meals once or more daily, and $63.2 \%$ reported that their last visit to the dentist was more than 6 months ago while $9.4 \%$ said they had never visited the dentist.

Women $(P<0.001)$, the more highly educated $(P<0.001)$, and those with higher economic status $(P=0.001)$ reported brushing their teeth more often. Consumption of sugary snacks and beverages between meals was more frequent among younger participants $(P=0.005)$ and more highly educated adults $(P=0.01)$, whereas using dental services within the past 6 months was more common among older participants

\begin{tabular}{|c|c|c|c|c|c|c|c|c|c|c|}
\hline & \multicolumn{4}{|c|}{ Tooth brushing, $\boldsymbol{n}(\%)$} & \multicolumn{3}{|c|}{$\begin{array}{c}\text { Sugary snacks and } \\
\text { beverages, } n(\%)\end{array}$} & \multicolumn{3}{|c|}{ Last dental visit, $n(\%)$} \\
\hline & $\geq 2 /$ day & 1/day & $<1 /$ day & $P^{*}$ & $<1$ time & $\geq 1$ time & $P^{*}$ & $\leq 6$ months & $>6$ months & $P^{*}$ \\
\hline \multicolumn{11}{|c|}{ Age (years) } \\
\hline $18-24$ & $87(34.7)$ & $115(45.8)$ & $49(19.5)$ & 0.6 & $81(32.4)$ & $169(67.6)$ & 0.005 & $74(29.5)$ & $177(70.5)$ & 0.01 \\
\hline $25-44$ & $192(39.6)$ & $201(41.4)$ & $92(19.0)$ & & $172(35.8)$ & $309(64.2)$ & & $197(40.8)$ & $286(59.2)$ & \\
\hline $45-65$ & $108(36.9)$ & $134(45.7)$ & $51(17.4)$ & & $132(45.1)$ & $161(54.9)$ & & $107(36.5)$ & $186(63.5)$ & \\
\hline \multicolumn{11}{|l|}{ Gender } \\
\hline Male & $152(30.2)$ & $223(44.2)$ & $129(25.6)$ & $<0.001$ & $183(36.5)$ & $319(63.5)$ & 0.4 & $176(35.1)$ & $325(64.9)$ & 0.2 \\
\hline Female & $235(44.8)$ & $227(43.2)$ & $63(12.0)$ & & $202(38.7)$ & $320(61.3)$ & & $202(38.4)$ & $324(61.6)$ & \\
\hline \multicolumn{11}{|c|}{ Education (years) } \\
\hline$<12$ & $80(28.7)$ & $124(44.4)$ & 75 (26.9) & $<0.001$ & $121(43.4)$ & $158(56.6)$ & 0.01 & $88(31.4)$ & $192(68.6)$ & 0.02 \\
\hline$\geq 12$ & $303(40.8)$ & $322(43.4)$ & $117(15.8)$ & & $259(35.1)$ & $478(64.9)$ & & $288(39.0)$ & $451(61.0)$ & \\
\hline \multicolumn{11}{|c|}{ Living area $^{\dagger}$} \\
\hline$<20$ & $89(30.2)$ & $135(45.8)$ & $71(24.1)$ & 0.001 & $111(37.9)$ & $182(62.1)$ & 0.8 & $89(30.3)$ & $205(69.7)$ & $<0.001$ \\
\hline $20-39$ & $187(38.6)$ & $220(45.4)$ & 78 (16.1) & & $176(36.4)$ & 307 (63.6) & & $179(37.0)$ & $305(63.0)$ & \\
\hline$\geq 40$ & $78(47.0)$ & $64(38.6)$ & $24(14.5)$ & & $65(39.2)$ & $101(60.8)$ & & $82(49.4)$ & $84(50.6)$ & \\
\hline
\end{tabular}

*Obtained by Chi-square, ${ }^{~} \mathrm{~m}^{2} / \mathrm{p}$ (square meters of living area per person) 
$(P=0.01)$, those with higher education $(P=0.02)$ and higher economic status $(P<0.001)$.

The results of multiple logistic regression analysis (both univariate and adjusted models) revealed female gender $(\mathrm{OR}=2.37,95 \%$ confidence interval $[\mathrm{CI}]$ : 1.66-3.38), higher education (OR highest level versus lowest level =1.86, 95\% CI: 1.25-2.77), and higher OHL scores (OR highest level versus lowest level $=1.97$, 95\% CI:1.30-2.98) as the most significant contributing factors to daily ( $\geq 1 /$ day) tooth brushing [Table 2].

In addition, advanced age $(\mathrm{OR}=1.01,95 \% \mathrm{CI}: 1.00-1.02)$ and higher OHL scores (OR highest level versus lowest level $=1.56,95 \%$ CI: $1.13-2.15$ ) remained the most significant factors related to infrequent use of sugary snacks or beverages $(<1 /$ day between meals) in the adjusted model [Table 3].

Finally, those with a large living area (OR highest level versus lowest level $=2.05,95 \%$ CI: $1.37-3.09$ ) and higher OHL scores (OR highest level versus lowest level $=1.59,95 \%$ CI: 1.15-2.21) reported frequent use of dental services ( $\leq 6$ months) [Table 4$]$.

\section{DISCUSSION}

\section{Tooth brushing}

The present study results revealed that Women, the more highly educated and those with higher OHL reported brushing their teeth more frequently. The present findings are in line with those of previous studies showing that higher socioeconomic status, ${ }^{[27,28]}$ OHL scores, ${ }^{[4,14,15]}$ and gender ${ }^{[28-30]}$ relate to more frequent tooth brushing. Gender differences in brushing habits may stem from women's desire to be more socially attractive. ${ }^{[31]}$

Moreover, female participants have shown higher levels of $\mathrm{OHL}^{[3]}$ than their male counterparts, probably due to their better skills in acting healthy. One out of ten participants, however, reported brushing their teeth rarely or never, indicating poor oral hygiene habits among a notable percentage of Iranian adults.

\section{Sugary drinks and snacks}

Diet and undoubtedly, sugar consumption contribute significantly to the development of dental caries. ${ }^{[32]}$ Nearly two-thirds of the participants in the present study reported consuming sugary drinks and snacks between meals once or more daily, reflecting poor dietary habits with respect to optimal dental health behavior. ${ }^{[22]}$

\begin{tabular}{|c|c|c|c|c|}
\hline & OR $(95 \% \mathrm{Cl})^{*}$ & $P$ & OR $(95 \% \mathrm{CI})^{\dagger}$ & $P$ \\
\hline Age & $1.00(0.99-1.01)$ & 0.64 & $1.00(0.99-1.02)$ & 0.25 \\
\hline \multicolumn{5}{|l|}{ Gender } \\
\hline Male & 1.00 (reference) & $<0.001$ & 1.00 (reference) & $<0.001$ \\
\hline Female & $2.52(1.81-3.51)$ & & $2.37(1.66-3.38)$ & \\
\hline \multicolumn{5}{|l|}{$\begin{array}{l}\text { Years of } \\
\text { education }\end{array}$} \\
\hline$<12$ & 1.00 (reference) & $<0.001$ & 1.00 (reference) & 0.002 \\
\hline$\geq 12$ & $1.96(1.41-2.73)$ & & $1.86(1.25-2.77)$ & \\
\hline \multicolumn{5}{|c|}{$\begin{array}{l}\text { Living area } \\
\left(\mathrm{m}^{2} / \mathrm{p}\right)\end{array}$} \\
\hline$<20$ & 1.00 (reference) & & 1.00 (reference) & \\
\hline $20-39$ & $1.65(1.15-2.37)$ & 0.006 & $1.41(0.96-2.06)$ & 0.07 \\
\hline$\geq 40$ & $1.87(1.12-3.11)$ & 0.01 & $1.54(0.91-2.63)$ & 0.10 \\
\hline \multicolumn{5}{|c|}{$\begin{array}{l}\text { Oral health } \\
\text { literacy } \\
\text { scores }\end{array}$} \\
\hline $0-9$ & 1.00 (reference) & & 1.00 (reference) & \\
\hline $10-11$ & $1.48(1.00-2.19)$ & 0.04 & $1.18(0.78-1.81)$ & 0.42 \\
\hline $12-17$ & $2.60(1.78-3.79)$ & $<0.001$ & $1.97(1.30-2.98)$ & 0.001 \\
\hline
\end{tabular}

\begin{tabular}{|c|c|c|c|c|}
\hline & OR $(95 \% \mathrm{CI})^{*}$ & $P$ & OR $(95 \% \mathrm{Cl})^{\dagger}$ & $P$ \\
\hline Age & $1.01(1.00-1.02)$ & $<0.001$ & $1.01(1.00-1.02)$ & 0.005 \\
\hline \multicolumn{5}{|l|}{ Gender } \\
\hline Male & 1.00 (reference) & 0.45 & 1.00 (reference) & 0.95 \\
\hline Female & $1.10(0.85-1.41)$ & & $1.00(0.76-1.32)$ & \\
\hline \multicolumn{5}{|l|}{$\begin{array}{l}\text { Years of } \\
\text { education }\end{array}$} \\
\hline$<12$ & 1.00 (reference) & 0.01 & 1.00 (reference) & 0.10 \\
\hline$\geq 12$ & $0.70(0.53-0.93)$ & & $0.75(0.54-1.05)$ & \\
\hline \multicolumn{5}{|c|}{$\begin{array}{l}\text { Living area } \\
\left(\mathrm{m}^{2} / \mathrm{p}\right)\end{array}$} \\
\hline$<20$ & 1.00 (reference) & & 1.00 (reference) & \\
\hline $20-39$ & $0.94(0.69-1.26)$ & 0.68 & $0.95(0.69-1.29)$ & 0.75 \\
\hline$\geq 40$ & $1.05(0.71-1.56)$ & 0.78 & $1.01(0.67-1.53)$ & 0.93 \\
\hline \multicolumn{5}{|c|}{$\begin{array}{l}\text { Oral health } \\
\text { literacy } \\
\text { scores }\end{array}$} \\
\hline $0-9$ & 1.00 (reference) & & 1.00 (reference) & \\
\hline $10-11$ & $1.26(0.90-1.77)$ & 0.16 & $1.26(0.88-1.81)$ & 0.20 \\
\hline $12-17$ & 1.40 (1.04-1.87) & 0.02 & $1.56(1.13-2.15)$ & 0.007 \\
\hline
\end{tabular}

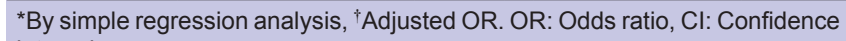
interval

Those among the study participants with higher education reported consuming more sugary drinks 


\begin{tabular}{|c|c|c|c|c|}
\hline & OR $(95 \% \mathrm{Cl})^{*}$ & $P$ & OR $(95 \% \mathrm{Cl})^{\dagger}$ & $P$ \\
\hline Age & $1.00(0.99-1.01)$ & 0.35 & $1.00(0.99-1.01)$ & 0.29 \\
\hline \multicolumn{5}{|l|}{ Gender } \\
\hline Male & 1.00 (reference) & 0.27 & 1.00 (reference) & 0.79 \\
\hline Female & $1.15(0.89-1.48)$ & & $1.03(0.78-1.36)$ & \\
\hline \multicolumn{5}{|l|}{$\begin{array}{l}\text { Years of } \\
\text { education }\end{array}$} \\
\hline$<12$ & 1.00 (reference) & 0.02 & 1.00 (reference) & 0.20 \\
\hline$\geq 12$ & $1.39(1.04-1.86)$ & & $1.24(0.88-1.75)$ & \\
\hline \multicolumn{5}{|l|}{$\begin{array}{l}\text { Living area } \\
\left(\mathrm{m}^{2} / \mathrm{p}\right)\end{array}$} \\
\hline$<20$ & 1.00 (reference) & & 1.00 (reference) & \\
\hline $20-39$ & $1.35(0.99-1.84)$ & 0.05 & $1.26(0.92-1.74)$ & 0.14 \\
\hline$\geq 40$ & $2.24(1.51-3.33)$ & $<0.001$ & 2.05 (1.37-3.09) & 0.001 \\
\hline \multicolumn{5}{|l|}{$\begin{array}{l}\text { Oral health } \\
\text { literacy } \\
\text { scores }\end{array}$} \\
\hline $0-9$ & 1.00 (reference) & & 1.00 (reference) & \\
\hline $10-11$ & $1.89(1.35-2.65)$ & $<0.001$ & $1.91(1.33-2.74)$ & $<0.001$ \\
\hline $12-17$ & $1.66(1.22-2.24)$ & 0.001 & $1.59(1.15-2.21)$ & 0.005 \\
\hline
\end{tabular}

and snacks than the less educated did. While adults on higher social levels consumed more sugar, Ghasemi et al. ${ }^{[30]}$ reported that Iranian dentists held poor attitudes toward sugar consumption as well. These findings raise great concern about this common unhealthy cultural habit. Authorities, health, and oral health partners appear to have good enough cause to offer a multidisciplinary common risk-factor approach, ${ }^{[33]}$ to increasing public awareness about the disadvantages of high sugar consumption.

Adjusting the model, however, revealed that age and OHL scores predict one's consumption of sugary drinks and snacks ( $<1$ / day between meals). This result indicates that all adults, and especially youngsters and those with limited literacy skills, should have access to easily understood messages about oral healthy diet.

\section{Dental visit}

Although the utilization of oral health services is based on specific individual needs and risk factors, ${ }^{[34]}$ regular dental visits can be considered a part of preventive oral health interventions. ${ }^{[23,35]}$ The present findings confirmed that a large percentage of the adult participants in this study visit the dentist infrequently, especially those with low economic status.

Similarly, Bayat et al. ${ }^{[35]}$ found a low rate of dental check-ups among Iranian adults and identified a positive relationship between socioeconomic status, having insurance, and dental care utilization. Therefore, providing primary health care or nationally subsidized public services, especially to deprived individuals that emphasize on preventive dental care such as regular dental check-ups in countries with developing oral health-care systems (e.g., Iran), might prove beneficial.

In line with the results of previous studies, ${ }^{[4,8,9]}$ the present study revealed a significant association between OHL scores and the use of dental services. This significant association remained even after adjusting for sociodemographic background factors, thus suggesting that the use of dental services may be an outcome related to OHL.

OHL and socioeconomic and demographic background factors predicted the study participants' OHB and use of dental services. While changing individuals' demographic and socioeconomic status poses an enormous challenge in all societies, increasing individuals' OHL level appears to offer great promise in improving OHB. Media and schools are two important settings for providing programs and interventions to improve the lay population's OHL. Research has found that individuals who received oral health information from multiple sources had higher OHL. ${ }^{[36]}$

\section{Limitations}

Social desirability in response to the self-assessment questions ${ }^{[37]}$ may have led to overestimation in tooth brushing frequency and use of dental services and to underestimation in reporting the consumption of sugary snacks and drinks in the present study. Consequently, one should exercise cautious when interpreting the results relating to self-reported health behavior.

\section{CONCLUSIONS}

Our study shows that OHL associated significantly with $\mathrm{OHB}$ and the use of dental services. We also found that Iranian elders consume fewer sugary snacks and drinks, women and the more highly educated report brushing their teeth more frequently, and those enjoy higher economic status tend to visit the dentist most often. In addition to multiple social determinants of $\mathrm{OHB}, \mathrm{OHL}$ reveals an opportunity to improve individuals' OHB. Therefore, the health-care system and oral health-care providers should address individuals with low OHL to reduce their barriers 
to care, particularly in countries with developing health-care services.

\section{Financial support and sponsorship Nil.}

\section{Conflicts of interest}

There are no conflicts of interest.

\section{REFERENCES}

1. National Institute of Dental and Craniofacial Research, National Institute of Health, U.S. Public Health Service, Department of Health and Human Services. The invisible barrier: Literacy and its relationship with oral health. A report of a workgroup sponsored by the National Institute of Dental and Craniofacial Research, National Institute of Health, U.S. Public Health Service, Department of Health and Human Services. J Public Health Dent 2005;65:174-82.

2. Horowitz AM, Kleinman DV. Oral health literacy: A pathway to reducing oral health disparities in Maryland. J Public Health Dent 2012;72 Suppl 1:S26-30.

3. Naghibi Sistani MM, Yazdani R, Virtanen J, Pakdaman A, Murtomaa H. Determinants of oral health: Does oral health literacy matter? ISRN Dent 2013;2013:249591.

4. Parker EJ, Jamieson LM. Associations between indigenous Australian oral health literacy and self-reported oral health outcomes. BMC Oral Health 2010;10:3.

5. Wehmeyer MM, Corwin CL, Guthmiller JM, Lee JY. The impact of oral health literacy on periodontal health status. J Public Health Dent 2014;74:80-7.

6. Griffey RT, Kennedy SK, D'Agostino McGowan L, Goodman M, Kaphingst KA. Is low health literacy associated with increased emergency department utilization and recidivism? Acad Emerg Med 2014;21:1109-15.

7. Hardie NA, Kyanko K, Busch S, Losasso AT, Levin RA. Health literacy and health care spending and utilization in a consumer-driven health plan. J Health Commun 2011;16 Suppl 3:308-21.

8. Calvasina P, Lawrence HP, Hoffman-Goetz L, Norman CD. Brazilian immigrants' oral health literacy and participation in oral health care in Canada. BMC Oral Health 2016;16:18.

9. Sabbahi DA, Lawrence HP, Limeback H, Rootman I. Development and evaluation of an oral health literacy instrument for adults. Community Dent Oral Epidemiol 2009;37:451-62.

10. Jamieson LM, Divaris K, Parker EJ, Lee JY. Oral health literacy comparisons between indigenous Australians and American Indians. Community Dent Health 2013;30:52-7.

11. Macek MD, Haynes D, Wells W, Bauer-Leffler S, Cotten PA, Parker RM. Measuring conceptual health knowledge in the context of oral health literacy: Preliminary results. J Public Health Dent 2010;70:197-204.

12. Jones M, Lee JY, Rozier RG. Oral health literacy among adult patients seeking dental care. J Am Dent Assoc 2007;138:1199-208.

13. Burgette JM, Lee JY, Baker AD, Vann WF Jr. Is dental utilization associated with oral health literacy? J Dent Res 2016;95:160-6.

14. Ueno M, Takeuchi S, Oshiro A, Kawaguchi Y. Relationship between oral health literacy and oral health behaviours and clinical status in Japanese adults. J Dent Sci 2013;8:170-6.

15. Khan K, Ruby B, Goldblatt RS, Schensul JJ, Reisine S. A pilot study to assess oral health literacy by comparing a word recognition and comprehension tool. BMC Oral Health 2014;14:135.

16. Vann WF Jr., Lee JY, Baker D, Divaris K. Oral health literacy among female caregivers: Impact on oral health outcomes in early childhood. J Dent Res 2010;89:1395-400

17. Brega AG, Thomas JF, Henderson WG, Batliner TS, Quissell DO, Braun PA, et al. Association of parental health literacy with oral health of Navajo Nation preschoolers. Health Educ Res 2016;31:70-81.

18. Blizniuk A, Ueno M, Zaitsu T, Kawaguchi Y. Association of oral health literacy with oral health behaviour and oral health status in Belarus. Community Dent Health 2015;32:148-52.

19. Lee JY, Divaris K, Baker AD, Rozier RG, Vann WF Jr. The relationship of oral health literacy and self-efficacy with oral health status and dental neglect. Am J Public Health 2012;102:923-9.

20. Naghibi Sistani MM, Montazeri A, Yazdani R, Murtomaa H. New oral health literacy instrument for public health: Development and pilot testing. J Investig Clin Dent 2014;5:313-21.

21. Attin T, Hornecker E. Tooth brushing and oral health: How frequently and when should tooth brushing be performed? Oral Health Prev Dent 2005;3:135-40.

22. Payne BJ, Locker D. Relationship between dental and general health behaviors in a Canadian population. J Public Health Dent 1996;56:198-204.

23. American Academy of Pediatric Dentistry. Guideline on periodicity of examination, preventive dental services, anticipatory guidance/ counseling, and oral treatment for infants, children, and adolescents. Pediatr Dent 2013;35:E148-56.

24. Iranian General Dentist Association (IGDA). Available from: http:// www.igda.webexir.com. [Last accessed on 2016 Apr 05].

25. Montazeri A, Goshtasebi A, Vahdaninia M. Educational inequalities in self-reported health in a general Iranian population. BMC Res Notes 2008;1:50.

26. Donyavi T, Naieni KH, Nedjat S, Vahdaninia M, Najafi M, Montazeri A Socioeconomic status and mortality after acute myocardial infarction: A study from Iran. Int J Equity Health 2011;10:9.

27. Lintula T, Laitala V, Pesonen P, Sipilä K, Laitala ML, Taanila A, et al. Self-reported oral health and associated factors in the North Finland 1966 birth cohort at the age of 31. BMC Oral Health 2014;14:155.

28. Yazdani R, Vehkalahti MM, Nouri M, Murtomaa H. Smoking, tooth brushing and oral cleanliness among 15-year-olds in Tehran, Iran. Oral Health Prev Dent 2008;6:45-51.

29. Rodakowska E, Kierklo A, Jamiolkowski J. Self-reported oral health behaviour among Scandinavian and Polish medical students studying in Poland. Cent Eur J Public Health 2016;24:68-75.

30. Ghasemi H, Murtomaa H, Vehkalahti MM, Torabzadeh H. Determinants of oral health behaviour among Iranian dentists. Int Dent J 2007;57:237-42.

31. Ronis DL, Lang WP, Farghaly MM, Passow E. Tooth brushing, flossing, and preventive dental visits by Detroit-area residents in relation to demographic and socioeconomic factors. J Public Health Dent 1993;53:138-45.

32. Zero DT, Moynihan P, Lingström P, Birkhed D. The role of dietary control. In: Fejerskov O, Kidd E, Nyvad B, Baelum V, editors. Dental Caries: The Disease and its Clinical Management. $2^{\text {nd }}$ ed. Oxford, U.K.: Blackwell Munksgaard; 2008. p. 330-65.

33. Brundtland H. Global Strategy for the Prevention and Control of Non-communicable Diseases. WHO (World Health Organization). Report Number: A53/14; 2000.

34. Patel S, Bay RC, Glick M. A systematic review of dental recall intervals and incidence of dental caries. J Am Dent Assoc 2010;141:527-39.

35. Bayat F, Vehkalahti MM, Zafarmand AH, Tala H. Impact of insurance scheme on adults' dental check-ups in a developing oral health care system. Eur J Dent 2008;2:3-10.

36. Sistani MM, Yazdani R, Virtanen J, Pakdaman A, Murtomaa H. Oral health literacy and information sources among adults in Tehran, Iran. Community Dent Health 2013;30:178-82.

37. Sjöström O, Holst D. Validity of a questionnaire survey: Response patterns in different subgroups and the effect of social desirability. Acta Odontol Scand 2002;60:136-40. 